\title{
Feasibility of optical coherence tomography angiography to assess changes in retinal microcirculation in ovine haemorrhagic shock
}

Maged Alnawaiseh ${ }^{1 \dagger}$, Christian Ertmer $^{2+}$, Laura Seidel ${ }^{2}$, Philip Helge Arnemann², Larissa Lahme, Tim-Gerald Kampmeier ${ }^{2}$, Sebastian Willy Rehberg ${ }^{3}$, Peter Heiduschka', Nicole Eter ${ }^{1+}$ and Michael Hessler ${ }^{2^{*+}}$ (D)

\begin{abstract}
Background: This study aimed to investigate the feasibility of optical coherence tomography angiography (OCT-A) for quantitative analysis of flow density to assess changes in retinal perfusion in an experimental model of haemorrhagic shock.

Methods: Haemorrhagic shock was induced in five healthy, anaesthetized sheep by stepwise blood withdrawal of $3 \times 10 \mathrm{~m} / \mathrm{kg}^{-1}$ body weight. OCT-A imaging of retinal perfusion was performed using an OCT device. Incident dark-field illumination microscopy videos were obtained for the evaluation of conjunctival microcirculation. Haemodynamic variables and flow density data in the OCT angiogram were analysed before and during progressive haemorrhage resulting in haemorrhagic shock as well as after fluid resuscitation with $10 \mathrm{ml} \cdot \mathrm{kg}^{-1}$ body weight of balanced hydroxyethyl starch solution (6\% HES 130/0.4). Videos of the conjunctival microcirculation were recorded at baseline, in haemorrhagic shock, and after resuscitation. Data are presented as median with interquartile range. Comparisons between time points were made using Friedman's test and the degree of correlation between two variables was expressed as Spearman's rank correlation coefficient.

Results: Mean arterial pressure and cardiac index $(\mathrm{Cl})$ decreased and lactate concentration increased after induction of shock, and haemodynamics recovered after resuscitation. The flow density in the superficial retinal OCT angiogram decreased significantly after shock induction (baseline $44.7 \%(40.3 ; 50.5)$ vs haemorrhagic shock $34.5 \%(32.8 ; 40.4) ; P=0.027)$ and recovered after fluid resuscitation $(46.9 \%(41.7 ; 50.7)$ vs haemorrhagic shock; $P=0.027$ ). The proportion of perfused vessels of the conjunctival microcirculation showed similar changes. The flow density measured using OCT-A correlated with the conjunctival microcirculation (perfused vessel density: Spearman's rank correlation coefficient $\rho=0.750, P=0.001$ ) and haemodynamic parameters $(\mathrm{Cl}: \rho=0.693, P<0.001)$.

Conclusions: Retinal flow density, measured using OCT-A, significantly decreased in shock and recovered after fluid therapy in an experimental model of haemorrhagic shock. OCT-A is feasible to assess changes in retinal perfusion in haemorrhagic shock and fluid resuscitation.
\end{abstract}

Keywords: Fluid therapy, Haemorrhagic shock, Microcirculation, Optical coherence tomography angiography, Sheep

\footnotetext{
* Correspondence: michael.hessler@uni-muenster.de

${ }^{\dagger}$ Maged Alnawaiseh, Christian Ertmer, Nicole Eter and Michael Hessler contributed equally to this work.

${ }^{2}$ Department of Anaesthesiology, Intensive Care, and Pain Therapy, University of Muenster Medical Centre, Albert-Schweitzer-Campus 1, Building A1, 48149 Muenster, Germany

Full list of author information is available at the end of the article
}

(c) The Author(s). 2018 Open Access This article is distributed under the terms of the Creative Commons Attribution 4.0 International License (http://creativecommons.org/licenses/by/4.0/), which permits unrestricted use, distribution, and reproduction in any medium, provided you give appropriate credit to the original author(s) and the source, provide a link to the Creative Commons license, and indicate if changes were made. The Creative Commons Public Domain Dedication waiver (http://creativecommons.org/publicdomain/zero/1.0/) applies to the data made available in this article, unless otherwise stated. 


\section{Background}

Blood flow in the microcirculation (vessels smaller than $100 \mu \mathrm{m}$ ) plays an important role in the delivery of oxygen and nutrients to cells. Maintaining adequate blood flow to the microcirculation is a prerequisite for normal organ perfusion and function. In critically ill patients, capillary blood flow is often impaired and changes in capillary perfusion are associated with outcome [1-4].

In acute haemorrhagic shock, excessive blood loss results in depressed cardiac output, which leads to decreased tissue perfusion with tissue hypoxia, organ dysfunction, and finally death. However, routine clinical parameters, which often serve as surrogates for monitoring of tissue perfusion in daily clinical practice (e.g. cardiac output, arterial blood lactate, heart rate, or urine output), do not always adequately reflect the level of tissue perfusion, and optimizing these parameters does not necessarily ensure adequate tissue perfusion [5-9]. In consequence, there is a need to introduce direct parameters of tissue perfusion (i.e. microcirculatory parameters) to support therapy decisions and to guide therapy in the future [5].

Using various novel techniques, it is possible to monitor patients' microcirculation directly at the bedside. Research using these new techniques has demonstrated the important role of the microcirculation in critical diseases $[3,4]$. The microcirculation in critically ill patients has been evaluated in the splanchnic region, skin, muscles, and the sublingual area [3]. In contrast, to our knowledge only a few studies evaluated changes in microvascular perfusion of the retina in critically ill patients, for example in sepsis [10].

The retina is an embryological projection of the forebrain. Impaired retinal perfusion might indicate reduced cerebral blood flow, since the ophthalmic artery arises from the internal carotid artery. Previous studies have shown a close relationship between cerebral events and qualitative measurements of retinal microvascular abnormalities [11-15].

Optical coherence tomography angiography (OCT-A) is a relatively novel technology, which provides high-resolution images of the retinal and choroidal vascularization. This method is non-invasive, reproducible, and can be quickly performed at the bedside. In consequence, this technology has attracted increasing interest over the last 2 years. It has been described in healthy subjects, in a range of ocular and systemic diseases in humans, and in various animal models [16-24].

The purpose of the current study is to evaluate the feasibility of OCT-A to assess the changes in retinal microcirculation in shock and fluid resuscitation in an experimental model of haemorrhagic shock in sheep.

\section{Methods}

\section{Anaesthesia and instrumentation}

After approval by the local veterinary authority (North Rhine-Westphalia State Environment Agency), five healthy female sheep (Ovis orientalis aries) with median (interquartile range) body weight of $53.7(48.8 ; 55.1) \mathrm{kg}$ were anaesthetized by intramuscular bolus injection of S-ketamine $\left(10 \mathrm{mg} \cdot \mathrm{kg}^{-1}\right)$ and midazolam $\left(0.3 \mathrm{mg} \cdot \mathrm{kg}^{-1}\right)$. The sheep were intubated endotracheally and mechanically ventilated throughout the experiment with a tidal volume of $10 \mathrm{ml} \cdot \mathrm{kg}^{-1}$ body weight, targeting an end tidal carbon dioxide pressure of $35 \pm 5 \mathrm{mmHg}$ by adjusting the respiratory rate. General anaesthesia and analgesia were maintained by continuous infusion of midazolam $\left(0.3 \mathrm{mg} \cdot \mathrm{kg}^{-1} \cdot \mathrm{h}^{-1}\right)$ and S-ketamine $\left(1 \mathrm{mg} \cdot \mathrm{kg}^{-1} \cdot \mathrm{h}^{-1}\right)$ throughout the experiment.

For haemodynamic monitoring and blood withdrawal, sheep were instrumented with a pulse contour cardiac output catheter (5-Fr $\mathrm{PiCCO}^{\text {тм }}$ catheter; Pulsion Medical Systems, Munich, Germany) in the left femoral artery, a central venous line in the right jugular vein, and a 7.5-French catheter in the left jugular vein. A Foley catheter in the urinary bladder was used to measure urine output.

\section{Experimental protocol}

Haemorrhagic shock was induced in the five sheep by withdrawal of $3 \times 10 \mathrm{ml}$ blood per kilogram of body weight according to an established protocol [25, 26], which corresponds to approximately 50-60\% of total blood volume in sheep [27]. After each step of blood withdrawal, a recovery period of $30 \mathrm{~min}$ was introduced to allow homeostasis to occur at the current level of hypovolemia. If the mean arterial pressure consistently dropped below $30 \mathrm{mmHg}$, the current withdrawal step was stopped for safety reasons (i.e. to prevent death) and the recovery period was started. After the third stage of blood withdrawal, haemorrhagic shock measurements were performed. After haemorrhagic shock measurements, fluid resuscitation was performed with an intravenous infusion of $10 \mathrm{ml} \cdot \mathrm{kg}^{-1}$ bodyweight of balanced hydroxyethyl starch solution (6\% HES 130/0.4) within $30 \mathrm{~min}$. Another set of measurements was taken after fluid resuscitation.

After reaching the resuscitation time point, all sheep were subjected to another experimental protocol not concerning the hypothesis of the present study. According to that protocol, sheep were killed at the end of the experiments by intravenous injection of $4 \mathrm{mg} \cdot \mathrm{kg}^{-1}$ propofol and $200 \mathrm{ml}$ potassium chloride solution (7.45\%).

\section{Measurements}

At baseline, at each stage of blood withdrawal, and after resuscitation, systemic haemodynamic variables were 
measured and blood samples were obtained for blood gas analysis.

Measured haemodynamic variables were cardiac index $(\mathrm{CI})$, central venous pressure (CVP), heart rate (HR), mean arterial pressure (MAP), and stroke volume index (SVI). The CI was obtained by threefold bolus thermodilution using the $\mathrm{PiCCO}^{\mathrm{m}}$ system and documenting the mean. MAP and the HR were read from the haemodynamic monitoring device. Blood gas analyses were performed with an ABL 725 Radiometer automatic blood gas analyser (Radiometer, Denmark).

\section{Optical coherence tomography angiography}

Imaging of the retinal vasculature was performed using the RTVue XR Avanti with AngioVue (Optovue Inc., Fremont, CA, USA). The instrument has an A-scan rate of 70,000 scans per second and uses a light source centred at $840 \mathrm{~nm}$ and a bandwidth of $50 \mathrm{~nm}$. Each OCT angiography volume contained $304 \times 304$ A-scans. Split-spectrum amplitude-decorrelation angiography was used to extract the OCT-A information. The OCT-A technology has been described previously in detail in other studies [18, 20, 28, 29]. Briefly, OCT scans of a certain region of the retina were performed repeatedly and OCT images were then evaluated for changes. Static tissue shows little or no change, whereas blood flow in the retinal and choroidal vessels will result in differences between consecutive scans [29]. Before imaging, pupils were dilated with phenylephrine (Neosynephrin ${ }^{\circ}$ 5\%; Ursapharm Arzneimittel GmbH, Saarbrücken, Germany) and tropicamide $5 \mathrm{mg} / \mathrm{ml}$ (Mydriaticum ${ }^{\circ}$ Stulln; Pharma Stulln GmbH, Stulln, Germany). The sheep were then placed in front of the OCT-A device. The cornea was lubricated before imaging and a lid speculum was used during imaging to keep the eye open. For orientation, a wide-field structural OCT scan and a $6 \times 6 \mathrm{~mm}^{2}$ or $8 \times 8 \mathrm{~mm}^{2}$ OCT-A scan were performed. To achieve high-quality imaging of the retinal microvasculature and for further analysis of the flow density, $3 \times 3 \mathrm{~mm}^{2}$ scans of the same retinal area were performed during the entire experimental procedure (Additional file 1). The eye tracking system and the follow-up mode were activated during imaging to allow analysis of the same retinal area. Only OCT-A images of good quality and a signal strength index $\geq 55$ were included. The software automatically segmented the retinal tissue into different retinal layers: superficial, deep, outer retina, and choriocapillaris. The segmentations of all examinations were checked before data analysis. The flow density data in the superficial OCT angiogram at baseline, after each step of bleeding, and after fluid resuscitation were then extracted and automatically analysed. In particular, the flow density of the central

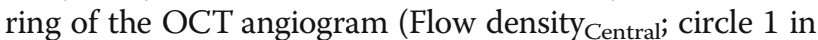
Fig. 1) and the flow density whole en face (Flow densitywF; the average flow density of circles 1 and 2 in Fig. 1) were calculated.

\section{Analysis of the conjunctival microcirculation}

Conjunctival microcirculation was measured with an incident dark-field (IDF) video microscope $\left(\right.$ CytoCam $^{\text {tw. }}$; Braedius Medical BV, Huizen, the Netherlands) at baseline, in haemorrhagic shock, and after resuscitation. For observation of the conjunctival microcirculation the opposite-side eye, which was not used for OCT angiography, was used to avoid affecting the conjunctival microcirculation with phenylephrine and tropicamide. At each time point at least five videos, each $5 \mathrm{~s}$ in length, were recorded. Videos of the conjunctival microcirculation were reviewed using previously described quality measures [30] and discarded if necessary. Analysis was conducted offline using dedicated software (AVA software version 3.2; Microvision Medical, Amsterdam, the Netherlands) according to the consensus conference criteria for analysis of the microcirculation in small vessels $(<20 \mu \mathrm{m})$ following established protocols [31-33]. At each time point, three to five high-quality videos of the conjunctival microcirculation were analysed in a blinded manner regarding the time point, and values of microvascular flow index (MFI), heterogeneity index (HI), total vessel density (TVD), perfused vessel density (PVD), and proportion of perfused vessels (PPV) were noted.

\section{Statistical analysis}

Microsoft Excel 2010 was used for data arrangement. Statistical analyses were performed using IBM SPSS $^{\circ}$ Statistics 24 for Windows (IBM Corporation, Somers, NY, USA). Due to the small sample size, non-parametric tests were used. Data are presented as median with interquartile range. Comparisons between time points were made using Friedman's test followed by a post hoc test (Dunn's multiple comparison test). The degree of correlation between two variables was expressed as Spearman's rank correlation coefficient. The global statistical significance level was set to 0.05 . Inferential statistics are intended to be exploratory (i.e. as a basis for hypotheses), rather than confirmatory, and are interpreted accordingly.

\section{Results}

At the end of the third step of blood withdrawal (haemorrhagic shock), a median $27(24 ; 30) \mathrm{ml} \cdot \mathrm{kg}^{-1}$ blood was shed from the animals (animal 1, $27 \mathrm{ml} \cdot \mathrm{kg}^{-1}$; animal 2, $30 \mathrm{ml} \cdot \mathrm{kg}^{-1}$; animal 3, $30 \mathrm{ml} \cdot \mathrm{kg}^{-1}$; animal $4,21 \mathrm{ml} \cdot \mathrm{kg}^{-1}$; animal 5, $\left.27 \mathrm{ml} \cdot \mathrm{kg}^{-1}\right)$. The MAP decreased significantly following blood loss (baseline 117 (108; 122) $\mathrm{mmHg}$ vs haemorrhagic shock $33(30 ; 38) \mathrm{mmHg} ; P=0.001)$ and increased almost to baseline levels after resuscitation (93 $(76 ; 100) \mathrm{mmHg}$ vs haemorrhagic shock; $P=0.164$ ). 

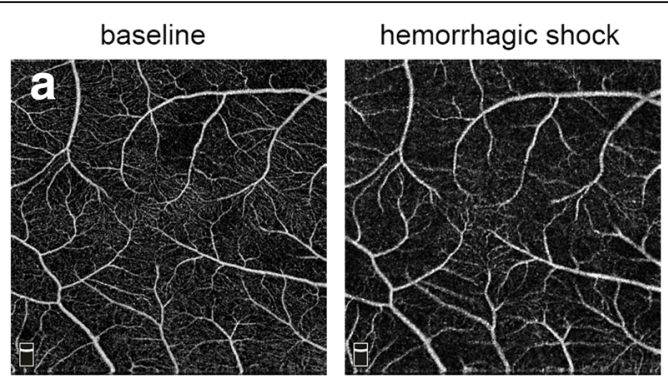

resuscitation
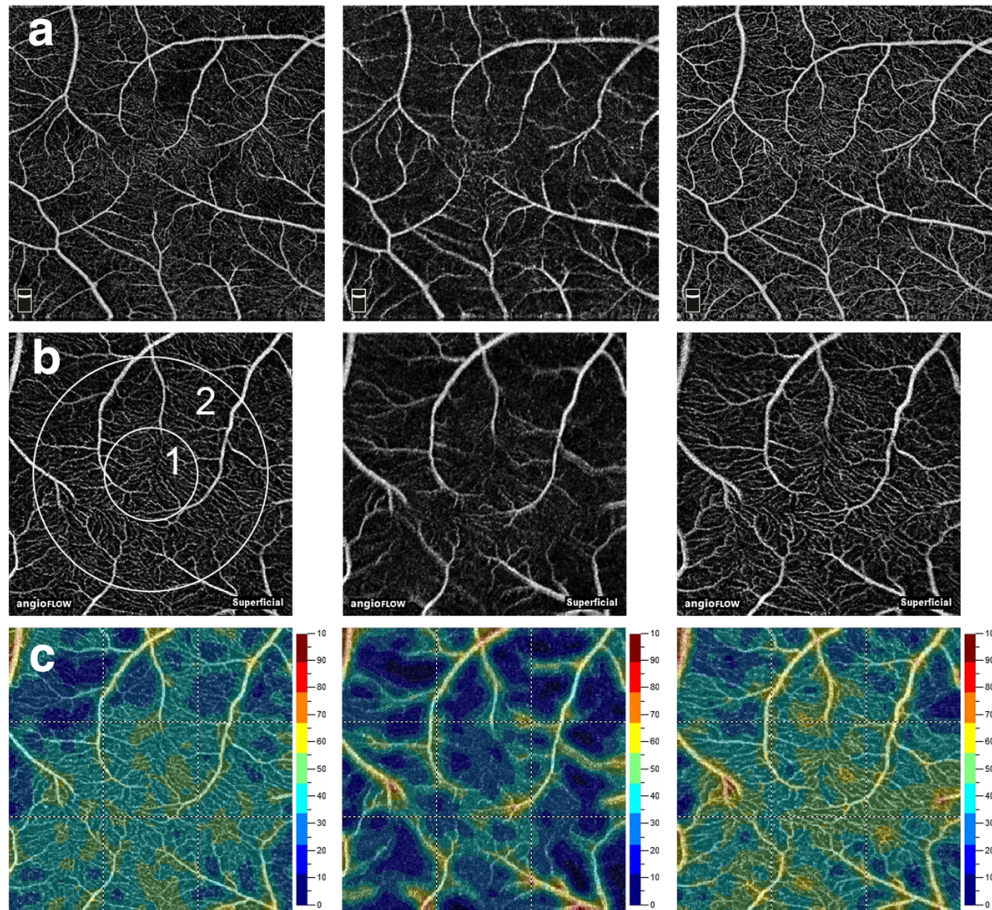

Fig. 1 Optical coherence tomography angiograms of retina. Optical coherence tomography (OCT) angiograms (a, b) and colour-coded OCT angiograms (c) of same area of sheep retina at baseline, in haemorrhagic shock, and after resuscitation. Circle 1 indicates region used for calculation of flow density (central ring). Flow density (whole en face) is average flow density of circles 1 and 2. a $6 \times 6 \mathrm{~mm}^{2}$ scans. b, c $3 \times 3 \mathrm{~mm}^{2}$ scans

The $\mathrm{CI}$ tended to decrease in haemorrhagic shock (1.1 $(0.8 ; 1.2) \mathrm{L} \cdot \mathrm{min}^{-1} \cdot \mathrm{m}^{-2}$ vs baseline $2.5(2.2 ; 2.7)$ $\left.\mathrm{L} \cdot \mathrm{min}^{-1} \cdot \mathrm{m}^{-2} ; P=0.051\right)$ and increased significantly after resuscitation $\left(3.0(2.7 ; 3.8) \mathrm{L} \cdot \mathrm{min}^{-1} \cdot \mathrm{m}^{-2}\right.$ vs haemorrhagic shock; $P=0.001$; Fig. 2).

Further haemodynamic variables at baseline, during progressive haemorrhage, and after resuscitation are summarized in Table 1.

The central venous oxygen saturation decreased significantly at the time of haemorrhagic shock compared to baseline (baseline $86.5 \%(84.0 ; 88.5)$ vs haemorrhagic shock $38.8 \%(29.4 ; 46.1) ; P=0.003)$ and increased to baseline levels after resuscitation (resuscitation 85.2\% (79.7; 89.2) vs haemorrhagic shock; $P=0.027$ ). Urine output and parameters of blood gas analyses at baseline, during progressive haemorrhage, and after resuscitation are summarized in Table 2.

With OCT-A imaging it was possible to visualize the optic disc and the retinal vasculature with very good image quality (Additional file 1). It was also possible to perform imaging of the same retinal area for several hours throughout the experimental procedure (Fig. 1). Figure 1 exemplifies the retinal vessels at baseline, during haemorrhagic shock, and after resuscitation. Flow density data of the same retinal area in a $3 \times 3 \mathrm{~mm}^{2}$ scan were also evaluated throughout the experimental procedure. Flow density ${ }_{W F}$ in the superficial OCT angiogram of the retina decreased significantly after shock induction (baseline $44.7 \%(40.3 ; 50.5)$ vs haemorrhagic shock $34.5(32.8 ; 40.4) \% ; P=0.027)$ and recovered to baseline values after resuscitation (resuscitation $46.9 \%$ (41.7; 50.7) vs haemorrhagic shock; $P=0.027$; Table 1 and Fig. 1).

The conjunctival microcirculation results are summarized in Table 3. The PPV decreased significantly at haemorrhagic shock compared to baseline values (baseline $100.0 \%(98.0 ; 100.0)$ vs haemorrhagic shock $72.0 \%$ (57.4; 76.3); $P=0.013$ ) and increased substantially after resuscitation (resuscitation 98.7\% (97.3; 99.1); $P=0.173$ vs haemorrhagic shock). The MFI decreased in haemorrhagic shock (baseline $3.1(3.0 ; 3.3)$ vs haemorrhagic shock $1.9(1.9 ; 2.1) ; P=0.034)$ and tended to increase after resuscitation $(3.0(3.0 ; 3.3)$ vs haemorrhagic shock; $P=0.081)$. Representative videos of the conjunctival microcirculation at baseline, in haemorrhagic shock, and after resuscitation are available as supplemental digital content (Additional files 2, 3 and 4).

Flow density ${ }_{W F}$ in the superficial retinal OCT angiogram correlated significantly with parameters of the conjunctival microcirculation (PVD: Spearman's rank 


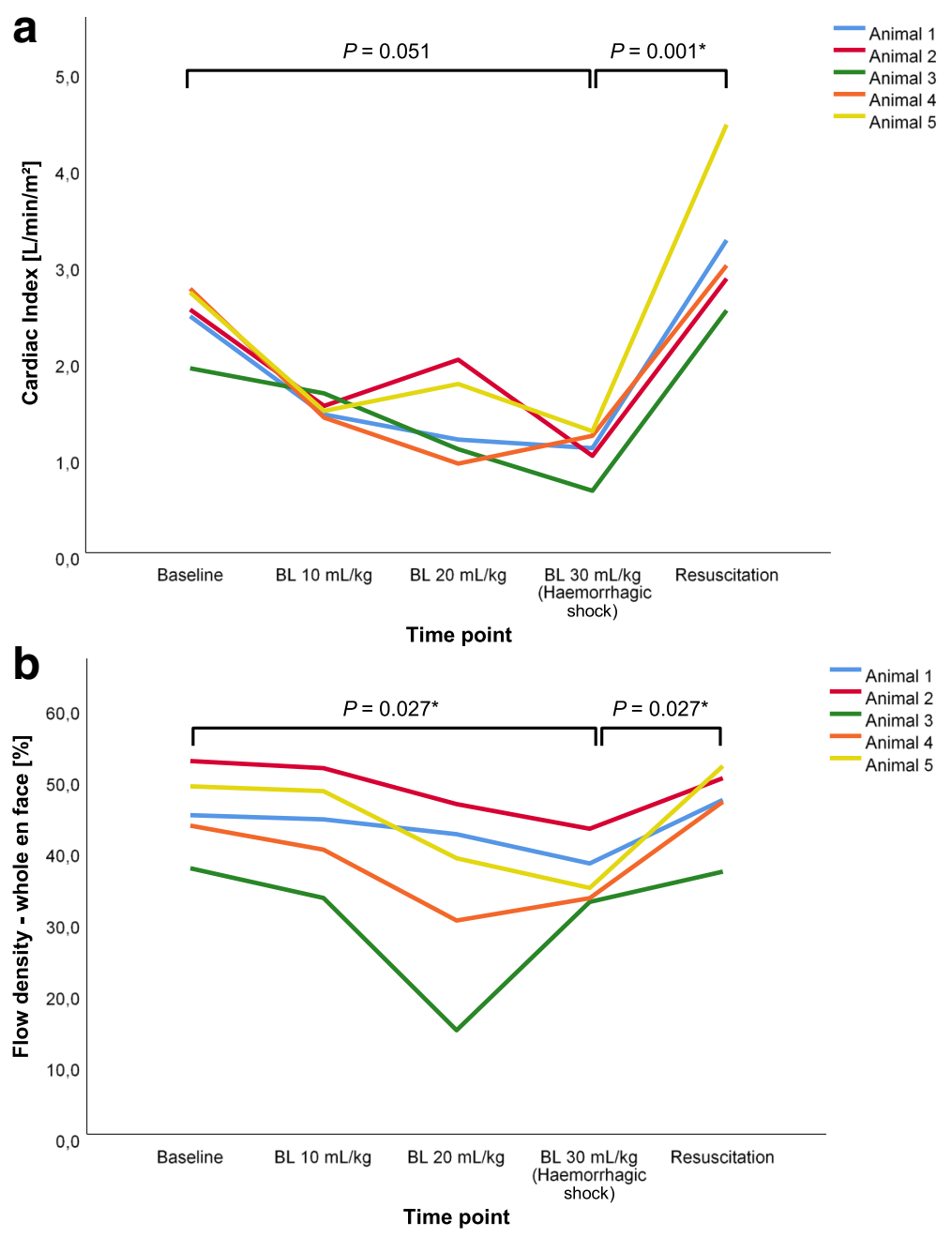

Fig. 2 Cardiac index and retinal flow density during progressive haemorrhage and after resuscitation. Changes in a cardiac index and $\mathbf{b}$ retinal flow density (whole en face) during progressive haemorrhage and after resuscitation for each individual animal $(N=5)$. ${ }^{*}$ Significant difference. BL blood loss

Table 1 Systemic haemodynamics and flow density of retina at baseline, during progressive haemorrhage, and after resuscitation

\begin{tabular}{|c|c|c|c|c|c|}
\hline \multirow[b]{2}{*}{ Parameter (unit) } & \multicolumn{5}{|l|}{ Time point } \\
\hline & Baseline & $\mathrm{BL} 10 \mathrm{ml} \cdot \mathrm{kg}^{-1}$ & $\mathrm{BL} 20 \mathrm{ml} \cdot \mathrm{kg}^{-1}$ & $\mathrm{BL} 30 \mathrm{ml} \cdot \mathrm{kg}^{-1}$ (haemorrhagic shock) & Resuscitation \\
\hline MAP (mmHg) & $117(108 ; 122)$ & $80(74 ; 98)$ & $44(37 ; 72)$ & $33(30 ; 38)^{*}$ & $93(76 ; 100)$ \\
\hline $\operatorname{HR}\left(1 \cdot \min ^{-1}\right)$ & $86(85 ; 94)$ & $98(84 ; 108)$ & $107(77 ; 118)$ & $107(92 ; 131)$ & $128(112 ; 139)^{*}$ \\
\hline $\mathrm{Cl}\left(\mathrm{L} \cdot \mathrm{min}^{-1} \cdot \mathrm{m}^{-2}\right)$ & $2.5(2.2 ; 2.7)$ & $1.5(1.4 ; 1.6)$ & $1.2(1.0 ; 1.9)$ & $1.1(0.8 ; 1.2)$ & $3.0(2.7 ; 3.8)^{\#}$ \\
\hline CVP $(\mathrm{mmHg})$ & $3(1 ; 10)$ & $6(3 ; 9)$ & $2(0 ; 11)$ & $0(0 ; 6)$ & $5(1 ; 9)$ \\
\hline $\mathrm{SVI}\left(\mathrm{ml} \cdot \mathrm{m}^{-2}\right)$ & $20(22 ; 41)$ & $17(15 ; 23)$ & $13(9 ; 18)$ & $11(6 ; 21)$ & $24(22 ; 24)$ \\
\hline \multicolumn{6}{|c|}{ Retinal microcirculation (OCT-A) } \\
\hline Flow density ${ }_{W F}(\%)$ & $44.7(40.3 ; 50.5)$ & $44.1(36.5 ; 49.7)$ & $38.7(22.2 ; 44.1)$ & $34.5(32.8 ; 40.4)^{*}$ & $46.9(41.7 ; 50.7)^{\#}$ \\
\hline Flow density Central $(\%)$ & $45.2(36.7 ; 48.6)$ & $43.4(34.3 ; 46.4)$ & $39.2(21.3 ; 42.2)^{\S}$ & $32.5(32.2 ; 40.0)^{\S}$ & $48.6(38.4 ; 50.3)$ \\
\hline
\end{tabular}

Values presented as median (interquartile range)

$B L$ blood loss, $\mathrm{Cl}$ cardiac index, CVP central venous pressure, Flow density Central $_{\text {flow density central ring, Flow density }}$ flow density whole en face, $H R$ heart rate,

$M A P$ mean arterial pressure, OCT-A optical coherence tomography angiography, SVI stroke volume index

*Significant difference vs baseline

\#Significant difference vs haemorrhagic shock

${ }^{\text {s }}$ Significant difference vs after resuscitation 
Table 2 Urine output and parameters of blood gas analysis at baseline, during progressive haemorrhage, and after resuscitation

\begin{tabular}{|c|c|c|c|c|c|}
\hline \multirow[b]{2}{*}{ Parameter (unit) } & \multicolumn{5}{|l|}{ Time point } \\
\hline & Baseline & $\mathrm{BL} 10 \mathrm{ml} \cdot \mathrm{kg}^{-1}$ & $\mathrm{BL} 20 \mathrm{ml} \cdot \mathrm{kg}^{-1}$ & BL $30 \mathrm{ml} \cdot \mathrm{kg}^{-1}$ (haemorrhagic shock) & Resuscitation \\
\hline Urine output $\left(\mathrm{ml} \cdot \mathrm{h}^{-1}\right)$ & $63(85 ; 105)$ & $20(8 ; 30)$ & $0(0 ; 3)^{*}$ & $0(0 ; 0)^{*}$ & $20(20 ; 28)$ \\
\hline $\mathrm{Hb}_{\mathrm{a}}\left(\mathrm{g} \cdot \mathrm{dl} \mathrm{l}^{-1}\right)$ & $9.0(8.9 ; 10.0)$ & $9.2(8.3 ; 9.6)^{\S}$ & $8.5(7.4 ; 8.6)$ & $7.4(7.1 ; 7.8)$ & $5.7(5.4 ; 6.2)^{*}$ \\
\hline $\mathrm{Hct}_{\mathrm{a}}(\%)$ & $27.8(27.5 ; 30.9)$ & $28.6(25.8 ; 29.6)^{\S}$ & $26.3(23.2 ; 27.0)$ & $23.0(22.2 ; 24.2)$ & $18.1(17.2 ; 19.4)^{*}$ \\
\hline $\mathrm{pH}$ & $7.39(7.35 ; 7.45)$ & $7.44(7.38 ; 7.47)$ & $7.44(7.39 ; 7.49)$ & $7.41(7.34 ; 7.46)$ & $7.29(7.26 ; 7.36)$ \\
\hline Lactate $\left(\mathrm{mmol} \cdot \mathrm{I}^{-1}\right)$ & $1.1(0.6 ; 1.2)$ & $0.7(0.4 ; 0.9)^{\S}$ & $1.0(0.7 ; 1.3)$ & $2.0(1.7 ; 3.4)$ & $3.8(3.4 ; 4.5)$ \\
\hline $\mathrm{S}_{\mathrm{CV}} \mathrm{O}_{2}$ & $87(84 ; 89)$ & $68(61 ; 76)$ & $50(33 ; 59)^{*}$ & $38.8(29.4 ; 46.1)^{*}$ & $85.2(79.7 ; 89.2)^{\#}$ \\
\hline
\end{tabular}

Values presented as median (interquartile range)

$B L$ blood loss, $\mathrm{Hb}_{a}$ arterial haemoglobin concentration, $\mathrm{Hct}_{a}$ arterial haematocrit, $\mathrm{S}_{c v} \mathrm{O}_{2}$ central venous oxygen saturation

*Significant difference vs baseline

\#Significant difference vs haemorrhagic shock

${ }^{\S}$ Significant difference vs after resuscitation

correlation coefficient $\rho=0.750, P=0.001$; PPV: Spearman's rank correlation coefficient $\rho=0.620, P=0.014$; MFI: Spearman's rank correlation coefficient $\rho=0.679$, $P=0.005$; see Fig. 3) and haemodynamic parameters (CI: Spearman's rank correlation coefficient $\rho=0.693$, $P<0.001$; MAP: Spearman's rank correlation coefficient $\rho=0.594, P=0.002$; SVI: Spearman's rank correlation coefficient $\rho=0.639, P=0.002$ ).

\section{Discussion}

The present study shows for the first time that OCT-A has potential as a novel technology for non-invasive and contactless monitoring of the retinal microcirculation during progressive haemorrhagic shock and resuscitation. Flow density ${ }_{W F}$ measured by OCT-A decreased significantly in haemorrhagic shock and recovered after resuscitation. The changes in Flow density $\mathrm{WF}_{\mathrm{F}}$ measured with OCT-A correlated with parameters of systemic haemodynamics and conjunctival microcirculation. The latter was analysed using IDF video microscopy and is the current gold standard for microcirculatory analyses.

In the current study, induction of haemorrhagic shock by removal of a large amount of blood resulted in typical changes in systemic haemodynamics, with reductions in cardiac index and a decrease in perfusion pressure. The drop in central venous oxygen saturation and increasing lactate concentrations may be interpreted as signs of tissue hypoperfusion and cellular oxygen deficit. To compensate, sheep reacted with an increase in heart rate and by recruiting fluid from the interstitium, as indicated by haemodilution (reflected by decreases in haematocrit and haemoglobin levels). These changes were accompanied by a reduced microvascular flow (MFI) and a drop in capillary perfusion (PPV) of the conjunctival microcirculation. These observations confirmed those obtained in previous studies on sheep in haemorrhagic shock $[25,26]$. We now show that these changes seen in systemic and microcirculatory variables during haemorrhagic shock and after resuscitation are closely correlated to OCT-A data of the retina. As the ophthalmic artery arises from the internal carotid artery, altered retinal perfusion may indicate impaired cerebral microcirculation. Many previous studies have shown a close relationship between cerebral events and qualitative measurements of retinal microvasculature [11-13, 15]. In this context, it should be mentioned that the brain and retina are controlled by a local autoregulatory mechanism in which the blood flow is regulated according to metabolic needs and oxygen consumption demands despite moderate variations in perfusion pressure [34]. In the current study, the relative maintenance of the retinal Flow density $\mathrm{WF}_{\mathrm{F}}$ after blood loss of $10 \mathrm{ml} \cdot \mathrm{kg}^{-1}$

Table 3 Parameters of conjunctival microcirculation at baseline, in haemorrhagic shock, and after resuscitation

\begin{tabular}{llll}
\hline & \multicolumn{1}{l}{ Time point } & & Resuscitation \\
\cline { 2 - 4 } Parameter (unit) & Baseline & Haemorrhagic shock & $18.5(15.1 ; 19.5)$ \\
\hline TVD $\left(\mathrm{mm} \cdot \mathrm{mm}^{-2}\right)$ & $15.4(13.7 ; 17.3)$ & $12.1(10.0 ; 13.8)$ & $16.0(15.3 ; 18.6)$ \\
PVD $\left(\mathrm{mm} \cdot \mathrm{mm}^{-2}\right)$ & $15.4(13.4 ; 17.3)$ & $72.0(57.4 ; 76.3)^{*}$ & $98.7(97.3 ; 99.1)$ \\
PPV $(\%)$ & $100.0(98.0 ; 100.0)$ & $1.9(1.9 ; 2.1)^{*}$ & $3.0(3.0 ; 3.3)$ \\
MFI & $3.1(3.0 ; 3.3)$ & $0.51(0.24 ; 0.73)^{*}$ & $0.12(0.33 ; 0.37)$ \\
HI & $0.10(0.05 ; 0.16)$ & &
\end{tabular}

Values presented as median (interquartile range)

$H I$ heterogeneity index, MFI microvascular flow index, PPV proportion of perfused vessel, $P V D$ perfused vessel density, TVD total vessel density

*Significant difference vs baseline 


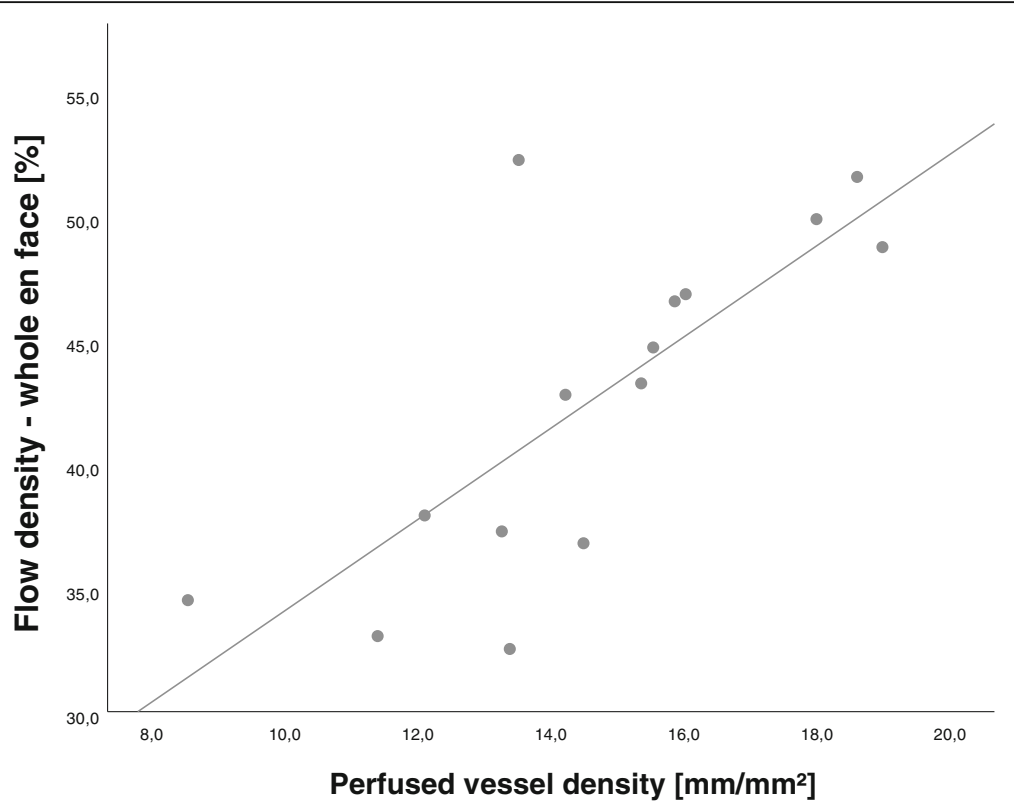

Fig. 3 Scatter diagram of retinal flow density (whole en face) and conjunctival perfused vessel density. Dots represent measurements at baseline, haemorrhagic shock, and resuscitation in the five animals

body weight in all sheep (Fig. 2), while MAP was reduced by approximately one third, may be interpreted as a MAP within the retinal autoregulatory range, while further blood loss undercut the retinal autoregulatory threshold, which was reflected by a drop in Flow density $\mathrm{WF}_{\mathrm{F}}$ in the current study. In this context, Park et al. [35] presented preliminary results of OCT-A analyses during haemorrhagic shock in rats and reported a constant retinal blood flow despite a drop in MAP. Although exact values were not reported, it may be hypothesized that the MAP remained above the threshold of autoregulation since they removed $40 \%$ of rat blood volume [35], as compared to about $60 \%$ in the present study. Against this background, Ono et al. [36] monitored the cerebral autoregulation response during cardiac surgery using near-infrared spectroscopy and showed that blood pressure excursions below the cerebral autoregulation threshold were associated with acute kidney injury. Therefore, further research may investigate the association between retina perfusion, assessed by OCT-A, and organ (dys)function.

Future clinical use of OCT-A to quantify tissue perfusion could be valuable in situations in which classical surrogates for monitoring of tissue perfusion, such as haemodynamic parameters or urine output, do not always adequately reflect the level of tissue perfusion (e.g. prolonged haemorrhagic or septic shock). Optimizing macro-haemodynamic parameters in this setting does not necessarily ensure adequate tissue perfusion [5-9]. However, the utility of OCT-A for these important issues needs to be evaluated in further experimental and clinical studies.
The present feasibility study demonstrates for the first time that, as a novel, non-invasive, and contactless technology, OCT-A can monitor microcirculatory perfusion during shock states in large animals. It may also have the potential to overcome some critical issues in monitoring microvascular perfusion, which impede the clinical use of methods to monitor the microcirculation [37]. In this context, a quantitative evaluation of the retinal microcirculation can be automatically performed with OCT-A without the need for intravenous dye injection [10]. The reproducibility of flow density measurements using OCT-A was evaluated in healthy subjects, in patients with different ocular and systemic diseases, and in different animal models [20, 21, 24, 28, 38]. In addition, by taking simple precautions, such as using a lid speculum, imaging in mydriasis, and lubrication of the cornea, blood flow can be analysed in the same retinal vessels of the same retinal area over the entire experimental period, which is not possible with most other methods of microvascular monitoring.

The fact that retinal perfusion, conjunctival microcirculation, and systemic haemodynamics showed a very close correlation is probably owed to the relatively homogeneous impairment of tissue perfusion in the early phase of haemorrhagic shock. It must be expected that results would be more heterogeneous in septic or other types of distributive shock. Heterogeneous changes in the microcirculation have been described previously $[39,40]$.

The utility of the innovative technology presented here in an intensive care setting remains to be evaluated in 
further experimental and clinical studies. In particular, the OCT-A instrument used in the current study needs a horizontal orientation of the ocular bulb, which is not feasible in critically ill humans. In this regard, Heidelberg Engineering, for example, recently presented the OCT FLEX device (with OCT-A module), which enables imaging on recumbent patients. However, there are further problems to be solved before OCT-A can be used routinely in critically ill patients as, for example, imaging in miosis (stimulant monitoring of the pupil reaction) or imaging through different media opacities (especially cataract in elderly patients).

\section{Limitations of the current study}

The main limitation of the present study is the small number of animals which were included in the study. This was due to a time-limited availability of the used OCT device. The results should show the feasibility of OCT-A to detect changes in retinal blood flow in haemorrhagic shock and were hypothesis generating in nature. Second, HES solutions were used for fluid resuscitation, which are contraindicated at present in critically ill patients due to suspected increases in renal failure [41], but may be used as plasma volume replacement following acute (sudden) blood loss (as was present in this study). In the current study, HES was chosen to investigate the immediate effect of fluid resuscitation on retinal perfusion and to show the feasibility of OCT-A to detect these changes. In this regard, the resuscitation protocol differs from current recommendations for management of major bleeding and haemorrhagic shock [42]. Another limitation of the study is the measurement of the conjunctival microcirculation instead of the sublingual microcirculation, which is the common region for microcirculatory measurements in critically ill patients $[1,6,32]$. Due to the head attachment of the sheep in prone position to the OCT device, it was not possible to measure the sublingual microcirculation in parallel with retinal perfusion. However, changes in sheep conjunctival microcirculation in haemorrhagic shock were shown to be comparable to changes in the sublingual microcirculation [43].

\section{Conclusions}

The current study shows for the first time that OCT-A is feasible to monitor retinal perfusion in sheep during experimental haemorrhagic shock and fluid resuscitation. We show that changes in retinal perfusion examined using OCT-A correlate with changes in systemic haemodynamic parameters and with variables of conjunctival microcirculation. This makes OCT-A a promising tool for in-vivo monitoring of the central microcirculation in critical illness. Further studies are needed to evaluate the utility of this technology in clinical practice.

\section{Additional files}

Additional file 1: Optical coherence tomography of retina. A. $4.5 \times 4.5 \mathrm{~mm}^{2}$ scan of optic nerve head $(\mathrm{ONH})$ showing large retinal vessels arising from $\mathrm{ONH}$. B. $6 \times 6 \mathrm{~mm}^{2}$ scan of retina showing retinal vessels; scans used for orientation alone. C. $3 \times 3 \mathrm{~mm}^{2}$ scan of retina providing high-quality visualization of the retinal microcirculation. (TIF $573 \mathrm{~kb}$ )

Additional file 2: Video of conjunctival microcirculation at baseline. Conjunctival microcirculation at baseline measured with incident dark-field (IDF) video microscope. (MP4 3467 kb)

Additional file 3: Video of conjunctival microcirculation in haemorrhagic shock. Conjunctival microcirculation in haemorrhagic shock measured with incident dark-field (IDF) video microscope. (MP4 4106 kb)

Additional file 4: Video of conjunctival microcirculation after resuscitation. Conjunctival microcirculation after resuscitation with hydroxyethyl starch solution (HES 130/0.4) measured with incident dark-field (IDF) video microscope. (MP4 3499 kb)

\section{Abbreviations}

Cl: Cardiac index; CVP: Central venous pressure; Flow density Central: Flow density central ring; Flow density wF: Flow density whole en face; HES: Hydroxyethyl starch solution; HI: Heterogeneity index; HR: Heart rate; IDF: Incident dark field; MAP: Mean arterial pressure; MFI: Microvascular flow index; OCT-A: Optical coherence tomography angiography; PPV: Proportion of perfused vessel; PVD: Perfused vessel density; SVI: Stroke volume index; TVD: Total vessel density

\section{Funding}

This study was supported by intramural funding of the Department of Anaesthesiology, Intensive Care and Pain Medicine, University Hospital of Muenster, Muenster, Germany.

\section{Availability of data and materials}

The datasets used and/or analysed during the current study are available from the corresponding author on reasonable request.

\section{Authors' contributions}

MA and CE were involved in conception of the study design, performed analysis on all samples, interpreted data, and wrote and revised the manuscript critically for important intellectual content. LS made substantial contributions to conception and design and acquisition of data, interpreted data, and participated in drafting and revising the manuscript critically for important intellectual content. PHA, LL, T-GK, SWR, and PH made substantial contributions to data interpretation and manuscript drafting, and gave final approval of the version to be submitted and any revised version. NE was involved in conception of the study design, performed analysis on all samples, interpreted data, and wrote and revised the manuscript critically for important intellectual content. MH was involved in conception of the study design, performed analysis on all samples, interpreted data, wrote the manuscript, and acts as corresponding author. All authors read and approved the final manuscript.

Ethics approval and consent to participate

The study was approved by the local veterinary authority (North RhineWestphalia State Environment Agency). Protocol number of the approval: 84-02.04.2016.A469.

\section{Competing interests}

T-GK received travel reimbursements and honoraria as a consultant from Fresenius Kabi Germany. SWR has received travel fees provided by Orion Pharma and Astellas Pharma, and is Medical Advisor for Fresenius Kabi Germany. MH has received travel fees provided by Amomed Pharma GmbH and Astellas Pharma. The remaining authors declare that they have no competing interests.

\section{Publisher's Note}

Springer Nature remains neutral with regard to jurisdictional claims in published maps and institutional affiliations. 


\section{Author details}

'Department of Ophthalmology, University of Muenster Medical Centre, Domagkstraße 15, 48149 Muenster, Germany. ${ }^{2}$ Department of Anaesthesiology, Intensive Care, and Pain Therapy, University of Muenster Medical Centre, Albert-Schweitzer-Campus 1, Building A1, 48149 Muenster, Germany. ${ }^{3}$ Department of Anaesthesiology, University of Greifswald, Ferdinand-Sauerbruch-Straße, 17475 Greifswald, Germany.

\section{Received: 15 February 2018 Accepted: 7 May 2018}

Published online: 29 May 2018

\section{References}

1. Edul VSK, Enrico C, Laviolle B, Vazquez AR, Ince C, Dubin A. Quantitative assessment of the microcirculation in healthy volunteers and in patients with septic shock. Crit Care Med. 2012;40:1443-8. https://doi.org/10.1097/ CCM.0b013e31823dae59.

2. Top APC, Ince C, de MN, van Dijk M, Tibboel D. Persistent low microcirculatory vessel density in nonsurvivors of sepsis in pediatric intensive care. Crit Care Med. 2011;39:8-13. https://doi.org/10.1097/CCM. 0b013e3181fb7994.

3. den Uil CA, Klijn E, Lagrand WK, Brugts JJ, Ince C, Spronk PE, Simoons ML. The microcirculation in health and critical disease. Prog Cardiovasc Dis. 2008;51:161-70. https://doi.org/10.1016/j.pcad.2008.07.002.

4. Erdem Ö, Kuiper JW, Tibboel D. Hemodynamic coherence in critically ill pediatric patients. Best Pract Res Clin Anaesthesiol. 2016;30:499-510. https:// doi.org/10.1016/j.bpa.2016.10.002.

5. Ince $\mathrm{C}$. The rationale for microcirculatory guided fluid therapy. Curr Opin Crit Care. 2014;20:301-8. https://doi.org/10.1097/MCC.0000000000000091.

6. Dubin A, Pozo MO, Casabella CA, Pálizas F, Murias G, Moseinco MC, et al. Increasing arterial blood pressure with norepinephrine does not improve microcirculatory blood flow: a prospective study. Crit Care. 2009;13:R92. https://doi.org/10.1186/cc7922.

7. Jhanji S, Stirling S, Patel N, Hinds CJ, Pearse RM. The effect of increasing doses of norepinephrine on tissue oxygenation and microvascular flow in patients with septic shock. Crit Care Med. 2009;37(6):1961. https://doi.org/10. 1097/CCM.0b013e3181a00a1c.

8. Klijn E, Den Uil CA, Bakker J, Ince C. The heterogeneity of the microcirculation in critical illness. Clin Chest Med. 2008;29:643-54, viii. https://doi.org/10.1016/j.ccm.2008.06.008.

9. Sun N, Luo W, Li LZ, Luo Q. Monitoring hemodynamic and metabolic alterations during severe hemorrhagic shock in rat brains. Acad Radiol. 2014; 21:175-84. https://doi.org/10.1016/j.acra.2013.11.017.

10. Erikson K, Liisanantti JH, Hautala N, Koskenkari J, Kamakura R, Herzig KH, et al. Retinal arterial blood flow and retinal changes in patients with sepsis: preliminary study using fluorescein angiography. Crit Care. 2017;21:86. https://doi.org/10.1186/s13054-017-1676-3.

11. Cooper LS, Wong TY, Klein R, Sharrett AR, Bryan RN, Hubbard LD, et al. Retinal microvascular abnormalities and MRI-defined subclinical cerebral infarction: the Atherosclerosis Risk in Communities Study. Stroke. 2006;37: 82-6. https://doi.org/10.1161/01.STR.0000195134.04355.e5.

12. Kawasaki R, Cheung N, Mosley T, Islam AFM, Sharrett AR, Klein R, et al. Retinal microvascular signs and 10-year risk of cerebral atrophy: the Atherosclerosis Risk in Communities (ARIC) study. Stroke. 2010;41(8):1826. https://doi.org/10.1161/STROKEAHA.110.585042.

13. Sharrett AR. A review of population-based retinal studies of the microvascular contribution to cerebrovascular diseases. Ophthalmic Epidemiol. 2007;14:238-42. https://doi.org/10.1080/09286580701396712.

14. Yatsuya H, Folsom AR, Wong TY, Klein R, Klein BEK, Sharrett AR. Retinal microvascular abnormalities and risk of lacunar stroke: Atherosclerosis Risk in Communities Study. Stroke. 2010;41:1349-55. https://doi.org/10.1161/ STROKEAHA. 110.580837

15. Hayashi H, Okamoto M, Kawanishi H, Matsuura T, Tabayashi N, Taniguchi S, Kawaguchi M. Ocular blood flow measured using laser speckle flowgraphy during aortic arch surgery with antegrade selective cerebral perfusion. J Cardiothorac Vasc Anesth. 2016;30:613-8. https:// doi.org/10.1053/j.jvca.2016.01.021.

16. Alnawaiseh M, Lahme L, Treder M, Rosentreter A, Eter N. Short-term effects of exercise on optic nerve and macular perfusion measured by optical coherence tomography angiography. Retina. 2017;37:1642-6. https://doi. org/10.1097/IAE.0000000000001419.
17. Alnawaiseh M, Brand C, Lauermann JL, Eter N. Messung der Flussdichte mittels OCT-Angiographie: Einfluss von Alter und Geschlecht. Ophthalmologe. 2017. [Epub ahead of print]. https://doi.org/10.1007/s00347-017-0539-2.

18. Yarmohammadi A, Zangwill LM, Diniz-Filho A, Suh MH, Yousefi S, Saunders $L J$, et al. Relationship between optical coherence tomography angiography vessel density and severity of visual field loss in glaucoma. Ophthalmology. 2016;123:2498-508. https://doi.org/10.1016/j.ophtha.2016.08.041.

19. Lévêque P-M, Zéboulon P, Brasnu E, Baudouin C, Labbé A. Optic disc vascularization in glaucoma: value of spectral-domain optical coherence tomography angiography. J Ophthalmol. 2016;2016:6956717. https://doi.org/ 10.1155/2016/6956717.

20. Jia Y, Wei E, Wang X, Zhang X, Morrison JC, Parikh M, et al. Optical coherence tomography angiography of optic disc perfusion in glaucoma. Ophthalmology. 2014;121:1322-32. https://doi.org/10.1016/j.ophtha.2014.01.021.

21. Alnawaiseh M, Schubert F, Heiduschka P. Eter N. Optical coherence tomography angiography in patients with retinitis pigmentosa. Retina. 2017. [Epub ahead of print]. https://doi.org/10.1097/IAE.0000000000001904.

22. Lanzillo R, Cennamo G, Criscuolo C, Carotenuto A, Velotti N, Sparnelli F, et al. Optical coherence tomography angiography retinal vascular network assessment in multiple sclerosis. Mult Scler. 2017:1352458517729463. https:// doi.org/10.1177/1352458517729463.

23. Alnawaiseh M, Rosentreter A, Hillmann A, Alex AF, Niekämper D, Heiduschka $P$, et al. OCT angiography in the mouse: a novel evaluation method for vascular pathologies of the mouse retina. Exp Eye Res. 2016;145:417-23. https://doi.org/10.1016/j.exer.2016.02.012.

24. Alnawaiseh M, Brand C, Bormann E, Wistuba J, Eter N, Heiduschka P. Quantitative analysis of retinal perfusion in mice using optical coherence tomography angiography. Exp Eye Res. 2017;164:151-6. https://doi.org/10. 1016/j.exer.2017.09.003.

25. Dubin A, Murias G, Estenssoro E, Canales H, Badie J, Pozo M, et al. Intramucosal-arterial PCO2 gap fails to reflect intestinal dysoxia in hypoxic hypoxia. Crit Care. 2002;6:514-20.

26. Dubin A, Pozo MO, Ferrara G, Murias G, Martins E, Canullán C, et al. Systemic and microcirculatory responses to progressive hemorrhage. Intensive Care Med. 2009;35:556-64. https://doi.org/10.1007/s00134-008-1385-0.

27. Hansard SL. Residual organ blood volume of cattle, sheep and swine. Proc Soc Exp Biol Med. 1956;91:31-4.

28. Li J, Yang Y-Q, Yang D-Y, Liu X-X, Sun Y-X, Wei S-F, Wang N-L. Reproducibility of perfusion parameters of optic disc and macula in rhesus monkeys by optical coherence tomography angiography. Chin Med J. 2016; 129:1087-90. https://doi.org/10.4103/0366-6999.180532.

29. Spaide RF, Fujimoto JG, Waheed NK. Image artefacts in optical coherence tomography angiography. Retina. 2015;35:2163-80. https://doi.org/10.1097/ IAE.00000000000000765.

30. Massey MJ, Larochelle E, Najarro G, Karmacharla A, Arnold R, Trzeciak S, et al. The microcirculation image quality score: development and preliminary evaluation of a proposed approach to grading quality of image acquisition for bedside videomicroscopy. J Crit Care. 2013;28:913-7. https://doi.org/10. 1016/j.jcrc.2013.06.015.

31. Massey MJ, Shapiro NI. A guide to human in vivo microcirculatory flow image analysis. Crit Care. 2016;20:35. https://doi.org/10.1186/s13054-0161213-9.

32. de Backer D, Hollenberg S, Boerma C, Goedhart P, Büchele G, Ospina-Tascon $\mathrm{G}$, et al. How to evaluate the microcirculation: report of a round table conference. Crit Care. 2007;11:R101. https://doi.org/10.1186/cc6118.

33. Ince C, Boerma EC, Cecconi M, de Backer D, Shapiro NI, Duranteau J, et al. Second consensus on the assessment of sublingual microcirculation in critically ill patients: results from a task force of the European Society of Intensive Care Medicine. Intensive Care Med. 2018; https://doi.org/10.1007/ s00134-018-5070-7.

34. Riva CE, Hero M, Titze P, Petrig B. Autoregulation of human optic nerve head blood flow in response to acute changes in ocular perfusion pressure. Graefes Arch Clin Exp Ophthalmol. 1997;235:618-26.

35. Park JR, Kim Y, Park T, Oh W-Y, Yune H, Lee JH, et al. 1423: Microcirculatory alternations in hemorrhagic shock and sepsis with optical coherence tomography. Crit Care Med. 2016;44:431. https://doi.org/10.1097/01.ccm. 0000510097.67054.8a.

36. Ono M, Arnaoutakis GJ, Fine DM, Brady K, Easley RB, Zheng Y, et al. Blood pressure excursions below the cerebral autoregulation threshold during cardiac surgery are associated with acute kidney injury. Crit Care Med. 2013; 41:464-71. https://doi.org/10.1097/CCM.0b013e31826ab3a1. 
37. Henzler D, Scheffler M, Westheider A, Köhler T. Microcirculation measurements: Barriers for use in clinical routine. Clin Hemorheol Microcirc. 2017;67(3-4):505-509. https://doi.org/10.3233/CH-179229.

38. Al-Sheikh M, Tepelus TC, Nazikyan T, Sadda SR. Repeatability of automated vessel density measurements using optical coherence tomography angiography. Br J Ophthalmol. 2017;101:449-52. https://doi.org/10.1136/ bjophthalmol-2016-308764.

39. Boerma EC, Kuiper MA, Kingma WP, Egbers PH, Gerritsen RT, Ince C. Disparity between skin perfusion and sublingual microcirculatory alterations in severe sepsis and septic shock: a prospective observational study. Intensive Care Med. 2008;34:1294-8. https:/doi.org/10.1007/s00134-008-1007-x.

40. Boerma EC, van der Voort Peter HJ, Spronk PE, Ince C. Relationship between sublingual and intestinal microcirculatory perfusion in patients with abdominal sepsis. Crit Care Med. 2007;35:1055-60. https://doi.org/10.1097/ 01.CCM.0000259527.89927.F9.

41. Rhodes A, Evans LE, Alhazzani W, Levy MM, Antonelli M, Ferrer R, et al. Surviving Sepsis Campaign: International Guidelines for Management of Sepsis and Septic Shock: 2016. Intensive Care Med. 2017;43:304-77. https:// doi.org/10.1007/s00134-017-4683-6.

42. Rossaint R, Bouillon B, Cerny V, Coats TJ, Duranteau J, Fernández-Mondéjar $E$, et al. The European guideline on management of major bleeding and coagulopathy following trauma: fourth edition. Crit Care. 2016;20:100. https://doi.org/10.1186/s13054-016-1265-x.

43. Arnemann P-H, Hessler M, Kampmeier T, Morelli A, van Aken HK, Westphal M, et al. Comparison of an automatic analysis and a manual analysis of conjunctival microcirculation in a sheep model of haemorrhagic shock Intensive Care Med Exp. 2016;4:37. https://doi.org/10.1186/s40635-016-0110-5.

Ready to submit your research? Choose BMC and benefit from:

- fast, convenient online submission

- thorough peer review by experienced researchers in your field

- rapid publication on acceptance

- support for research data, including large and complex data types

- gold Open Access which fosters wider collaboration and increased citations

- maximum visibility for your research: over $100 \mathrm{M}$ website views per year 